\title{
Acoustic Resonance Classification of Swimbladder-Bearing Fish
}

\author{
Timothy K. Stanton and Dezhang Chu \\ Applied Ocean Physics and Engineering Department \\ Woods Hole Oceanographic Institution \\ Bigelow 201, MS \#11 \\ Woods Hole, MA 02543 \\ phone: (508) 289-2757 \\ fax: (508) 457-2194_email: tstanton@whoi.edu \\ J. Michael Jech \\ Northeast Fisheries Science Center \\ 166 Water Street \\ Woods Hole, MA 02543 \\ e-mail: michael.jech@noaa.gov
}

Award Number: N00014-04-1-0440

http://www.whoi.edu/people/tstanton

\section{LONG-TERM GOALS}

To understand and exploit the resonance scattering by swimbladder-bearing fish (typically in the $1-10 \mathrm{kHz}$ frequency region). Exploitation of the resonances can significantly reduce ambiguities in interpreting acoustic scattering in terms of meaningful biological parameters compared with traditional higher frequency approaches and other lower frequency narrowband approaches.

\section{OBJECTIVES}

To conduct a new class of quantitative acoustic studies of scattering by swimbladder-bearing fish utilizing new broadband-acoustic technology that is optimized for use in the resonance scattering region of fish.

\section{APPROACH}

This research was principally focused on taking advantage of a modified commercial system that was originally designed for marine geological and gas/oil exploration. It was especially attractive for use in studying swimbladder-bearing fish because this system was optimized for use in the frequency band in which swimbladders may resonate. The off-the-shelf sensors on the system (in particular, the transmitters and receivers) were selected and configured in a manner best suited for the fish application. The system was used for studying distributions of fish in their natural habitat. The research was part of a NOAA/NMFS fisheries study and included trawling for sampling the fish and traditional high frequency echo sounders for comparison. Data were interpreted in terms of physics-based scattering models whose parameters may be 


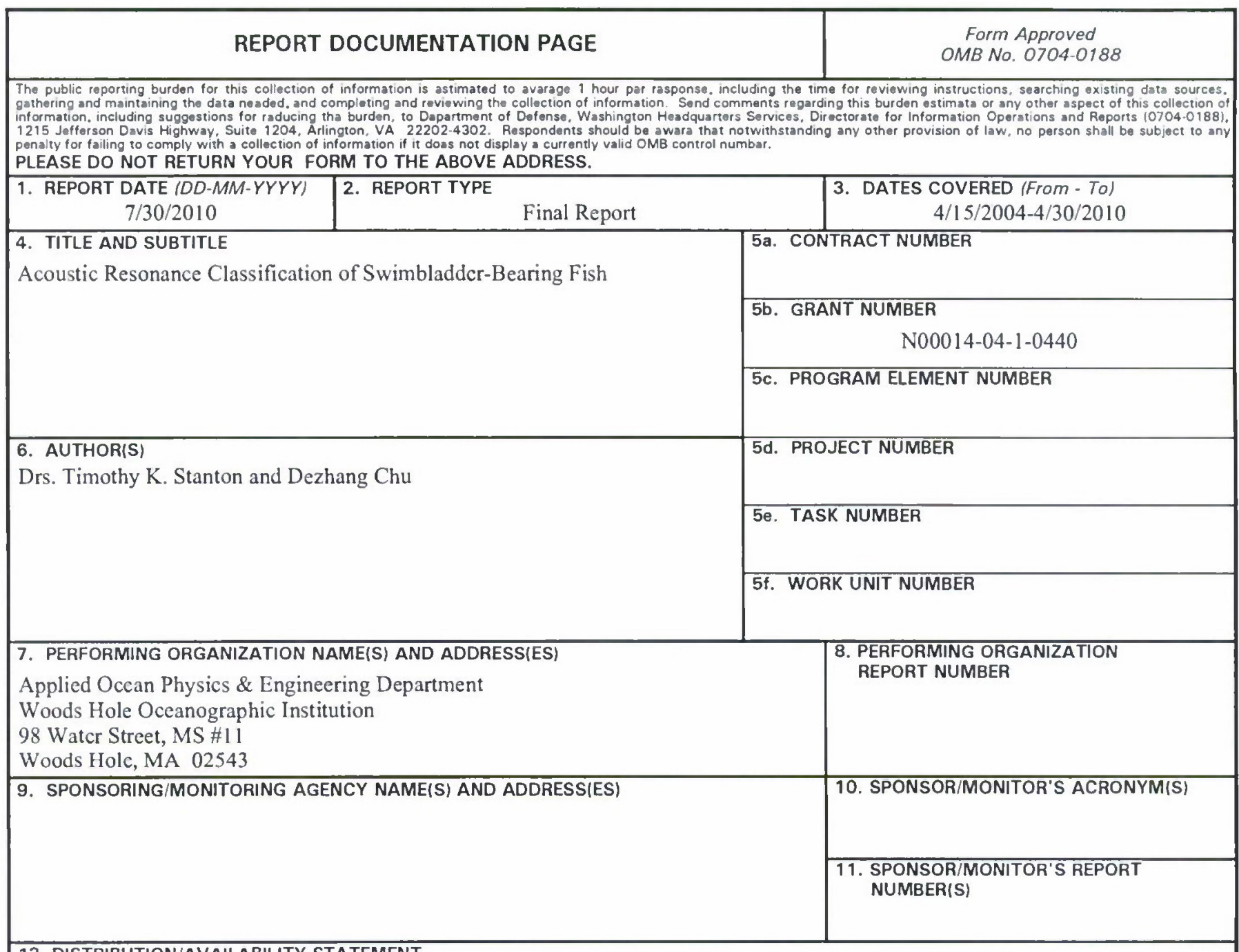

\section{DISTRIBUTION/AVAILABILITY STATEMENT}

Approved for public release; distribution is unlimited

13. SUPPLEMENTARY NOTES

14. ABSTRACT

Sce attached report

15. SUBJECT TERMS

\begin{tabular}{|c|c|c|c|c|c|}
\hline \multicolumn{3}{|c|}{ 16. SECURITY CLASSIFICATION OF: } & \multirow{3}{*}{$\begin{array}{l}\text { 17. LIMITATION OF } \\
\text { ABSTRACT } \\
\text { UL }\end{array}$} & \multirow{3}{*}{$\begin{array}{l}\text { 18. NUMBER } \\
\text { OF } \\
\text { PAGES } \\
12\end{array}$} & \multirow{2}{*}{$\begin{array}{l}\text { 19a. NAME OF RESPONSIBLE PERSON } \\
\text { Dr. Timothy K. Stanton }\end{array}$} \\
\hline a. REPORT & b. ABSTRACT & c. THIS PAGE & & & \\
\hline UL & UL & UL & & & $\begin{array}{l}\text { 19b. TELEPHONE NUMBER (Inc/ude area code) } \\
508-289-2757\end{array}$ \\
\hline
\end{tabular}


determined empirically as a result of the measurements. Tim Stanton oversaw the entire program and was involved in every aspect. Jim Irish participated in early system design and tests. Dezhang Chu participated in finalizing system specifications, conducted the system calibration, participated in the first two at-sea studies, and processed/analyzed data. Cindy Sellers participated in the second and third at-sea studies and processed/analyzed data. Mike Jech conducted the biological sampling, performed high frequency acoustic surveys, and was involved in the design and execution of the cruises. NRL (led by Roger Gauss) participated in the third cruise in a pilot study to use their prototype mid-frequency broadband system for longrange detection and classification of fish.

\section{ACCOMPLISHMENTS}

The accomplishments are based on a series of three scientific cruises in a major fishing ground (over or near Georges Bank) involving both a feasibility demonstration of each of the broadband acoustic systems, as well as the use of the Edgetech-WHOI system to study fish (Fig. 1). New insight was developed about the spatial distributions of fish, especially with mixed assemblages and their associated predator-prey relationships. Through this research process, advanced techniques were developed associated with broadband acoustic signal processing of fish echoes. The accomplishments are summarized:

\section{Cruises:}

Each cruise involved use of mid-frequency active acoustics in combination with high frequency narrowband acoustics (for direct comparison with traditional acoustic techniques) and net samples for biological data (Figs. 2-6).

2005: Pilot experiment in which the Edgetech-WHOI system was applied for the first time to study swimbladder-bearing fish. The feasibility study was a success: the broadband system routinely observed resonances of fish with acceptable signal-to-noise ratios across the band. Also, with the matched-filter processing, the fish were observed at high range resolution. The final "product" of this study was a map of numerical density of fish free of the ambiguities that normally plague high frequency narrowband systems (Fig. 7). Part of the "path" to these accomplishments involved developing new techniques for calibration of broadband systems and use of broadband signals for quantitative studies of fish, as well as a new scattering model for resonant fish that spans two decades of frequencies (more details below).

2007 and 2008: Using the Edgetech-WHOl system as a "tool" to study fish distributions:

-Patchiness of the fish was characterized, showing first-of-a-kind data as a result of towing the broadband Edgetech system deep, within $20 \mathrm{~m}$ of the bottom-dwelling fish. The transition from isolated fish to patches of fish (i.e. exhibiting social behavior) was illustrated and the statistics quantified (Fig. 8). 
-Studying mixed assemblages of fish. The broadband Edgetech system provided unique firstof-a-kind data by revealing the spatial distribution of small and large fish (separately) within patches. Although these fish could not be spatially resolved with the acoustics system (in spite of its high range resolution), the fish could be resolved spectrally through use of the broadband acoustics. Specifically, separate and resolvable resonances were observed for the two different size classes of fish and as a function of location within a patch (Figs. 9, 10). This unique study revealed how both predator and prey species of fish were collocated indicating that other ecological forces made it attractive for the prey to reside in this part of the water column.

Pilot experiment in a limited geographical area using NRL broadband long-range sonar to studying resonance structure and patchiness of fish on a large scale $(100 \mathrm{sq} . \mathrm{km})$ :

-The feasibility study was a success as resonances at $3 \mathrm{kHz}$ were observed at distances as great as $10 \mathrm{~km}$ (Fig. 11). Furthermore, the echoes from the patches of fish were coherent, i.e. "survived" matched-filter normalization, indicating that fish are a significant source of clutter in the mid-frequencies (left panel of Fig. 11; Fig. 12). The importance of this system spans both science and Navy applications: Science: For long-range mapping of distributions of fish, ambiguities can be eliminated over other long-range systems that are narrowband. For example, the resonance frequency of fish (such as the Atlantic herring in our studies) may depend strongly upon their depth and, hence, whether it is day or night. As a result, during a diurnal migration, a narrowband long-range system might detect the fish before the migration (when the resonance frequency is near the frequency of the system). However, after the migration, the narrowband system might not detect the fish (when the resonance frequency becomes far from the narrowband frequency). This issue can be addressed through use of a broadband system that might detect both resonance frequencies, before and after migration, as a result of the wide range of frequencies the system uses. Navy: Biologics are now well known to be a significant source of clutter. However, existing Navy classifiers do not account for biologics, given the general lack of quantitative information. This system, with its broadband capabilities, can be used to parameterize the clutter field with the goal of improving clutter rejection in Navy classifiers. Information on the fish resonance structure vs. depth can also be used to guide waveform selection, by in situ minimizing the overlap of the signal band with the resonance band (e.g., different signal bands for day and night operations).

\section{$\underline{\text { Refereed papers: }}$}

To date, the research funded by this grant (ONR-Biology, N00014-04-1-0440), in combination with a related grant (ONR Undersea Signal Processing, grants N00014-07-1-0232 and N0001409-1-0428) whose analysis uses the mid-frequency data collected under this grant, has led to four major manuscripts submitted to and/or published in refereed journals (three in print, one submitted) collectively describing the following (Stanton and Chu, 2008, 2010; Stanton et al., 2010, submitted-a).

1. Concept of the broadband resonance approach

2. Specifications of the new Edgetech system

3. New broadband calibration techniques developed and its ocean application 
4. System-operation equations involving broadband signal processing (i.e., converting broadband matched filter data into standard quantities of target strength and volume scattering strength)

5. Observation of the swimbladder resonances

6. New physics-based model of the resonances

7. Applying all of the new methods and data for the estimation of fish size and density across a number of patches. As mentioned above, this approach results in significantly reduced ambiguities over traditional high frequency approaches as well as other prototype lower frequency approaches, both of which are outside of the resonance regime and narrowband. With this broadband acoustics approach we could therefore unambiguously deduce that the fish in a large dense patch were the same size as the fish in a neighboring smaller and sparser patch.

8. Distinguishing bottom-dwelling fish from the seafloor using the high range resolution of the downward-looking broadband system. This helps address important biological questions about the spatial distribution of bottom-dwelling fish (traditional acoustic and net systems cannot quantify these distributions), such as the correlation of seafloor properties with fish presence/abundance.

9. Discriminating between fish and zooplankton (and sizing the zooplankton with the broadband scattering signature). Because of the resonance properties of the fish and the fact that the scattering by zooplankton is negligible at the resonance frequencies, the scattering data from the entire range of frequencies $(1-100 \mathrm{kHz})$ allowed us to make definitive statements about the types of organisms belonging to various patches observed in the ocean.

10. Physics-based characterization of the non-Rayleigh nature of the echoes from patches of fish over a series of scattering geometries (at short ranges). The controlled data (along with net samples) allowed us to connect the physics of the scattering and scattering geometry (along with sonar parameters) to accurately characterize the statistical behavior of the echoes. This is important in accounting for clutter in Navy classifiers (co-funded by ONR Biology and Undersea Signal Processing).

11. Resonance classification of mixed assemblages. Here, the real power of the broadband system was demonstrated and applied to obtain new insight into a complex biological problem. The system was used to study several aggregations of fish in which there were two distinct size classes $-3-5 \mathrm{~cm}$ long and $15-25 \mathrm{~cm}$ long. Although the fish were not spatially resolvable with the system, they were resolved spectrally. The different classes of fish were detected through the different peaks in the echo spectrum (Figs. 9, 10). The data reveal that each size class of fish was distributed throughout each aggregation, indicating that both predator and prey were co-existing. This suggests that the presence of predators on the prey was offset by other appealing environmental factors.

Stanton, T.K. and D. Chu (2008) "Calibration of broadband active systems using a single standard spherical target," J. Acoust. Soc. Am. 124, 128-136. (funded solely by this grant)

Stanton, T.K., D. Chu, J.M. Jech, and J.D. lrish. (2010). "New broadband methods for resonance classification and high-resolution imagery of fish with swimbladders using a modified 
commercial broadband echosounder". ICES J. Mar. Sci. 67: 365-378 (funded solely by this grant)

Stanton, T.K. and D. Chu (2010), "Non-Rayleigh echoes from resolved individuals and patches of resonant fish at 2-4 kHz," IEEE J. Ocean. Eng., vol 35: 152-163. (co-funded by ONR Undersea Signal Processing)

Stanton, T.K., C.J. Sellers, and J.M. Jech (submitted-a). "Resonance classification of mixed assemblages of fish with swimbladders using a broadband acoustic echosounder at 1-6 kHz." Submitted to Can. J. Fish. Aq. Sci. (funded solely by this grant)

\section{Pilot studv results in conference proceedings}

Work has been completed concerning the pilot experiment involving resonance classification and characterization of patchiness over large scales $(10 \mathrm{~km})$ using the NRL horizontal-looking longrange system (Figs.1 1, 12). Through use of the beamformed data, we have been able to study the spatial and temporal variability of the distributions of fish. For example, the energy-normalized matched filtered data showed significant variability in the echoes, both spatially (using a towed horizontal line receive array) and temporally (using fixed-station vertical line receive array) (Figs. I 1, 12). Furthermore, the echoes showed a strong resonance of about $3 \mathrm{kHz}$ at ranges as great as $10 \mathrm{~km}$ (Fig. II), which is consistent with swimbladder resonances of the fish present. These data, in combination with net samples made near the measurements, illustrate the highly variable nature of the distributions of fish, both in space and time.

This work has appeared in print in the following proceedings:

Gauss, R.C., J.M. Fialkowski, E.L. Kunz, R. Menis, T.K. Stanton, C.J. Sellers, and J.M. Jech (2009), "Clutter variability due to fish aggregations: mid-frequency measurements in the Gulf of Maine," in Proceedings of The $3^{\text {rd }}$ International Conference \& Exhibition on "Underwater Acoustic Measurements: Technologies and Results," ed. J.S. Papadakis and L. Bjorno, 2I-26 June 2009, Nafplion, Peloponnese, Greece (F.O.R.T.H., Hellas, Greece), pp. 459-466.

\section{$\underline{\text { Review paper }}$}

In addition to the above scholarship concerning new results, Stanton was invited by the Marine Acoustics Society of Japan to write a review of the past 20 years of broadband acoustic scattering research conducted by the WHOI bioacoustics group (active acoustics component). The work describes the various laboratory measurements of broadband acoustic scattering by zooplankton, fish, squid, benthic shells, and machined objects, the scattering models developed that were inspired and grounded by the measurements, signal processing associated with broadband acoustics techniques, and field work to date (including this project) involving use of broadband sound to study marine organisms (Stanton, 2009). 
Stanton, T.K. (2009), "Broadband acoustic sensing of the ocean," J. Marine. Acoust. Soc. Jpn. 36, 95-107.

\section{Press release and parallel development of zooplankton/turbulence system}

In parallel to the development and application of the broadband system for resonance classification of fish was a broadband system developed by Lavery and colleagues, made by the same company, for broadband classification of zooplankton and turbulence. Many of the major developments funded first under this current ONR grant (Biology) were later applied to the development in another ONR grant (Ocean Acoustics; SW06 program), leading to the paper:

Lavery, A. C., Chu, D., and Moum, J. N. 2010. Measurements of acoustic scattering from zooplankton and oceanic microstructure using a broadband echosounder. J. Mar. Sci. 67: 379394.

This paper was published side-by-side with the Stanton et al. (2010) paper listed above.

Collectively, these two systems span the frequency range $1.5 \mathrm{kHz}-600 \mathrm{kHz}$ and can study fish, zooplankton, and turbulence. The Stanton and Lavery papers describe at-sea demonstrations of the systems as well as extensive development of new methods, including broadband calibration, converting matched filter output into the standard quantities of target strength and volume backscattering strength, and physics-based scattering model interpretation of the data. Given the importance of the work, a press release was published:

http://www. whoi.edu/page.do?pid $=7545 \& \mathrm{tid}=282 \& \mathrm{cid}=70786 \& \mathrm{ct}=162$

Various media and news organizations have published forms of the press release, including Science News, Lifescience world, Environment 360, USA Today, and Powerboat World.

\section{Echo statistics research inspired by this work and funded by other program}

Normally, a report on one project only reports on the results funded by that project. However, we wish to point out that the analysis co-funded by this grant and the one in Undersea Signal Processing not only led to a (co-funded) paper (Stanton and Chu, 2010), but it has led to two other papers, solely funded by Undersea Signal Processing, involving development of a general physics-based echo statistics model and application to clutter data collected by a Navy midfrequency sonar (Chu and Stanton, 2010; Stanton et al., submitted-b):

I. Physics-based predictions of non-Rayleigh echo probability density functions (PDF's) as a result of a short-range directional sonar and finite numbers of patches of scatterers. The 
analysis in (10) above inspired the development of this general theory for characterizing the statistical properties of the echo from any type of patch or multiple patches in the sonar beam (fish, seafloor, etc.).

2. The general theoretical formulation in \#1 has been used to interpret clutter data from three distinct classes of clutter as measured by a Navy midfrequency system. This represents a physics-based interpretation of the clutter, where the number of scattering features within a clutter echo were inferred. The clutter was divided into three classes, one of which was biological in origin.

Chu, D. and T.K. Stanton (2010), "Statistics of echoes from a directional sonar beam insonifying finite numbers of single scatterers and patches of scatterers," IEEE J. Ocean. Eng., vol. 35, 267277. (funded solely by Undersea Signal Processing)

Stanton, T.K., D. Chu, J.M. Gelb, and G.L. Tipple (submitted-b), "Physics-based interpretation of echo statistics of three distinct clutter classes measured with a midfrequency active sonar," submitted to IEEE J. Ocean. Eng. (funded solely by Undersea Signal Processing)

\section{Future Naval Relevance}

Stanton is making plans with Drs. Brian LaCour and Jim Gelb of ARL/UT to transition the new knowledge that was originally inspired by analyzing the statistics of the Edgetech echoes to an advanced Navy active sonar simulator. The next step in the transition is our planned participation in the upcoming ONR HiFAST FNC (Future Naval Capabilities) program with Mike Vaccaro (Code 321 ) as Program Officer. The product of this program would be various algorithmic tools specific to predicting bioclutter in active mid-frequency systems. The HiFAST program is targeting several simulator applications: SAST, NAVAIR, and IUSS. A planning letter for this program has been submitted by Stanton, and Stanton and Gauss were participants in the August 2009 HiFAST workshop at ARL/UT. The new general theory on echo statistics described above has already been successfully applied to active mid-frequency sonar data collected by an operational Navy system involving three classes of clutter (Stanton et al., submitted-b). The key aspect to the theory is that it is physics-based, connects the physics of the scattering (and associated stochastic elements such random-roughness and speckly patches) and the directionality of the sonar (and associated stochastic component due to patches that are randomly located in the beam) to the statistical properties of the echoes (and, specifically, probability of false alarm).

Commencing in FY10, Gauss is participating on a PEO C4I \& Space (PMW 120; Marcus Speckhahn) panel to help develop a phenomenological approach that can nowcast/forecast spatial distributions of biologics for mid-frequency ASW applications based on oceanographic, biologic, and acoustic data and models. Gauss is also on the ONR 321 (Kevin Williams) Applied

Reverberation Modeling Board (ARM-B) whose charter it is to understand the limitations/major challenges presented by today's and tomorrow's active sonars relative to reverberation and clutter predictive capabilities, and recommend solutions (the way ahead). Its initial focus is on mid-frequency active monostatic sonars. Both of these high-profile positions allow Gauss to 
identify and act on technology insertion points. Additionally, Gauss has in transition to CNMOC's Oceanographic and Atmospheric Master Library (OAML) the first Navy-standard Fish Scattering Strength (FSS) algorithm. The planned Stanton enhancements to his scattering formulations could serve as a basis of FSS upgrades. Gauss has been developing moment-based clutter-rejection techniques that could be feed into the Echo-Tracker-Classifier (ECT) baseline processor developed/maintained for the Navy's surface ships' MF active sonars by ARL:UT (Karl Fisher). Gauss is also in contact with NUWC (Wendy Petersen) regarding providing bioclutter data as a potential upgrade to the Characterization and Reduction of Active False Tracks (CRAFT) database.

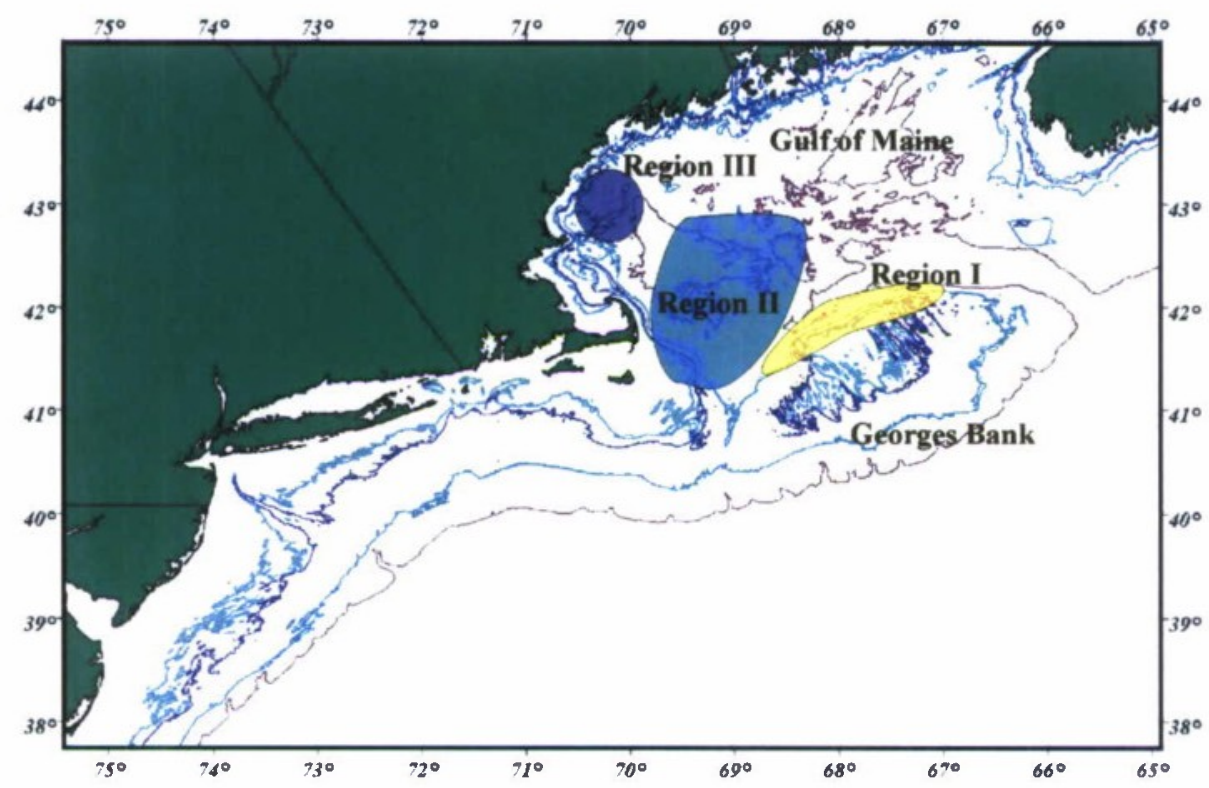

Figure I. The September 2005, 2007, and 2008 cruises took place mostly in Region I and, to some extent, Region III. Future cruises will focus on Region I, and to some extent, Regions II and III. The three regions were chosen as they represent varying degrees of complexity in species composition. The pelagic species in Region I are dominated by Atlantic herring during the fall. Although herring frequently dominate the composition of aggregations of fish, there are also mixes of species including silver hake, red hake, butterfish, redfish, and pearlsides, all of which contain swimbladders. 


\section{Ocean Experiment-Two Mid-Frequency Systems}

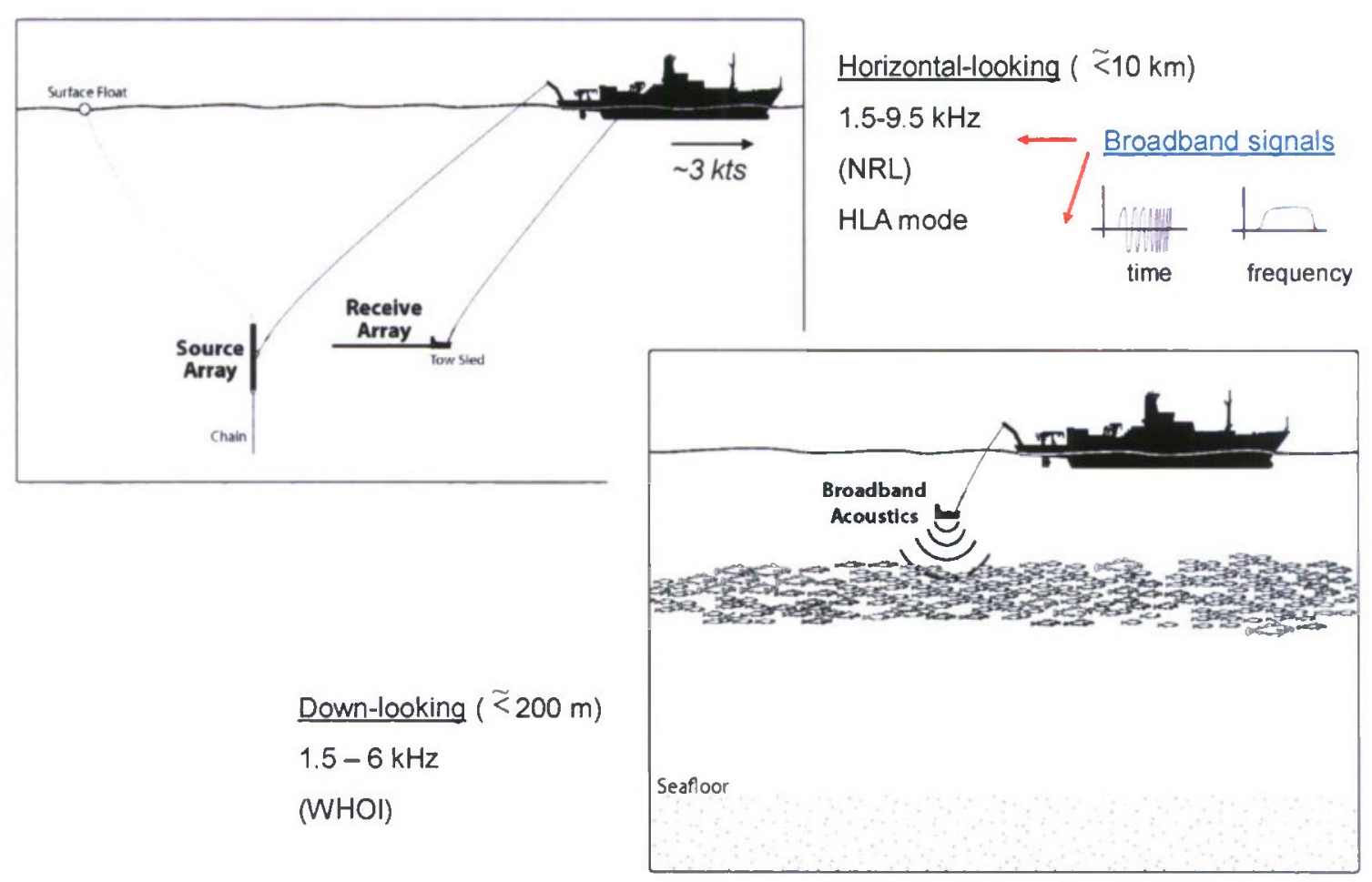

Figure 2. Deployment configuration for the two broadband mid-frequency active acoustic systems. When used in the same experiment, the two systems are deployed in sequence from the same vessel. 


\section{WHOI Down-looking, Modified-Echosounder System}
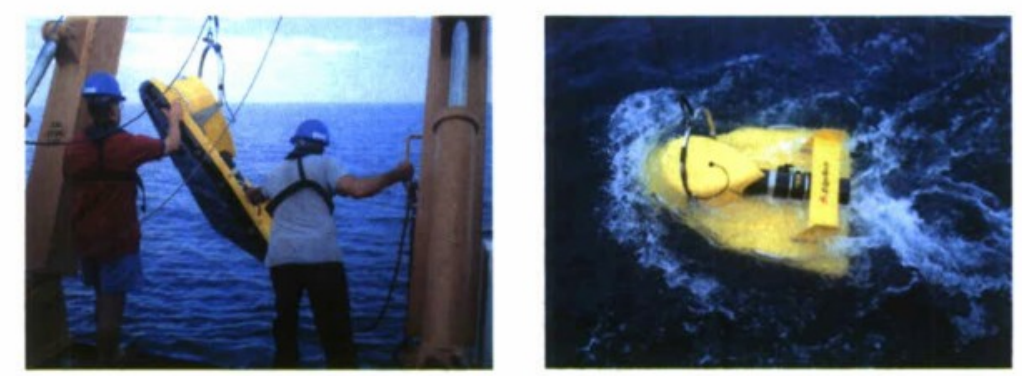

Underside of Towbody

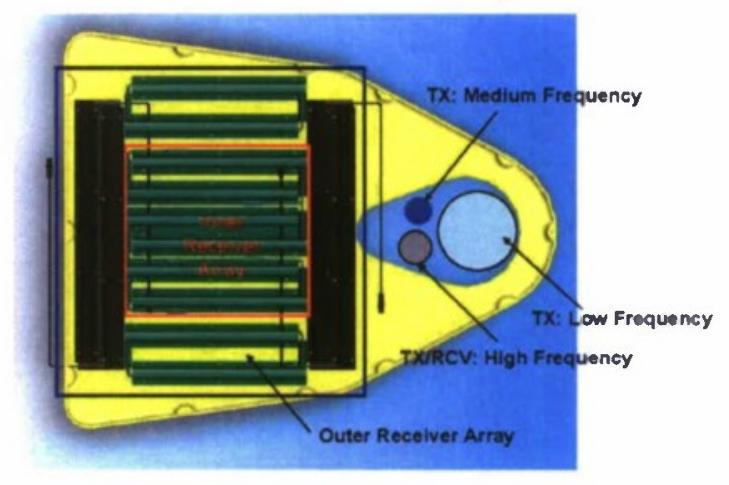

4-Channel System

$1.5-6 \mathrm{kHz}$

$4-20 \mathrm{kHz}$

$30-70 \mathrm{kHz}$

$50-110 \mathrm{kHz}$

Figure 3. Broadband active acoustics system used for short-range downward-looking detection of fish. 


\section{NRL MF Long-Range System}
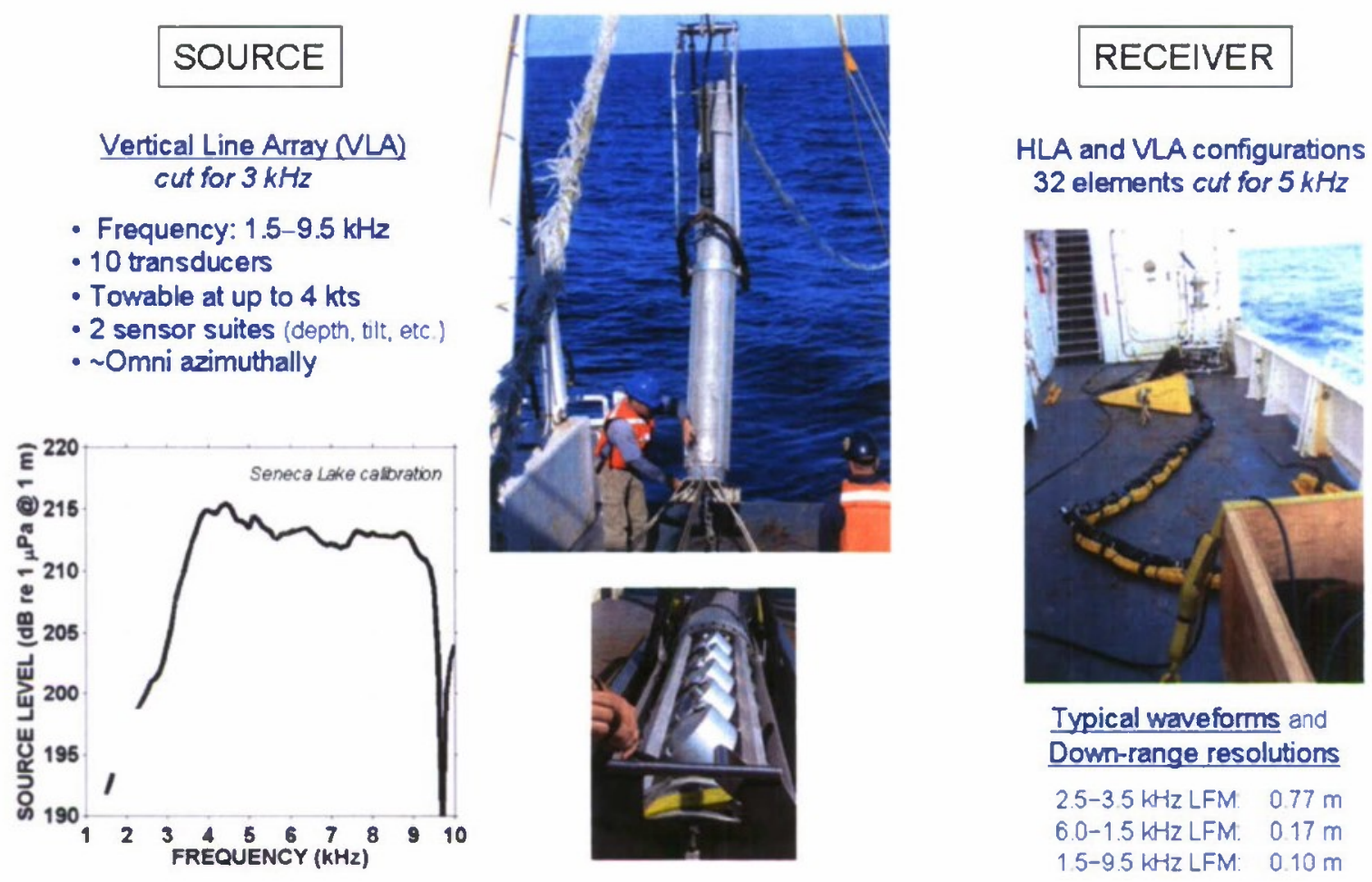

Figure 4. Broadband active acoustics system used for long-range horizontal-looking detection of fish. 


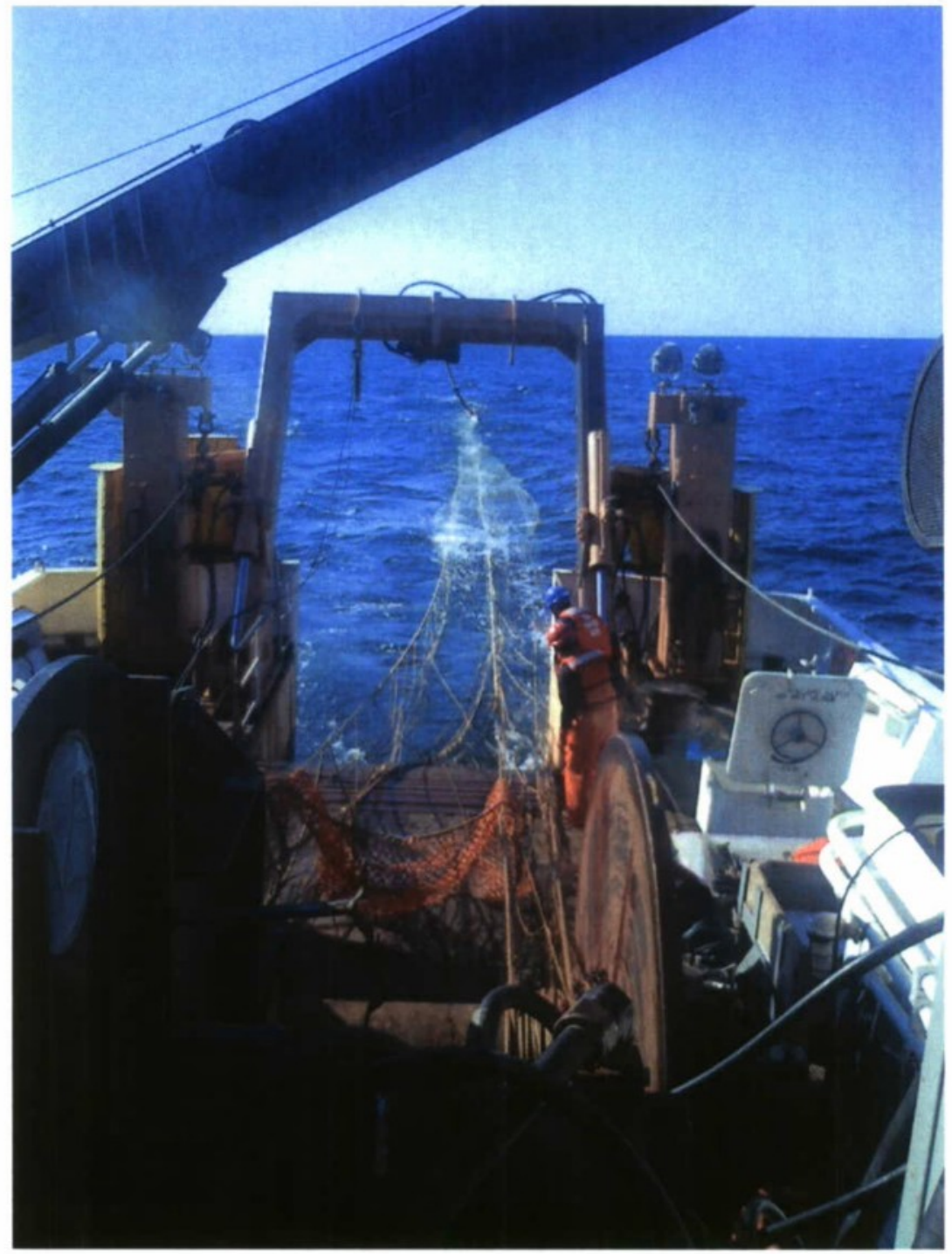

Figure 5. Pelagic trawl, provided by the National Marine Fisheries Service, streaming out behind the ship before being lowered down to depth. 

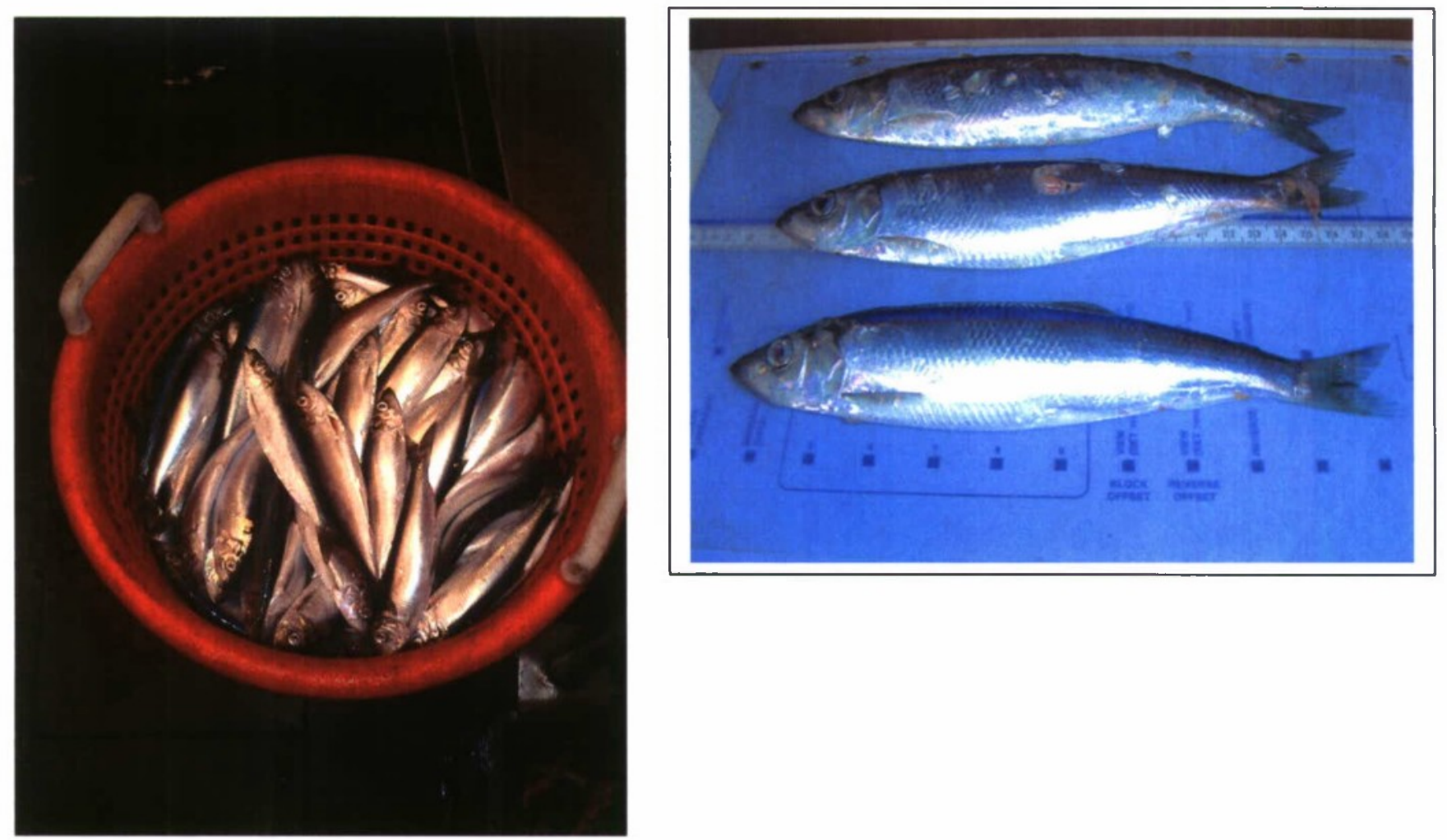

Figure 6a. Atlantic Herring sampled over Georges Bank. These were generally the dominant scatterers in the aggregations of fish. Euphausiids (two laid on top of middle fish, right panel) and other zooplankton and fish were also caught in the nets.

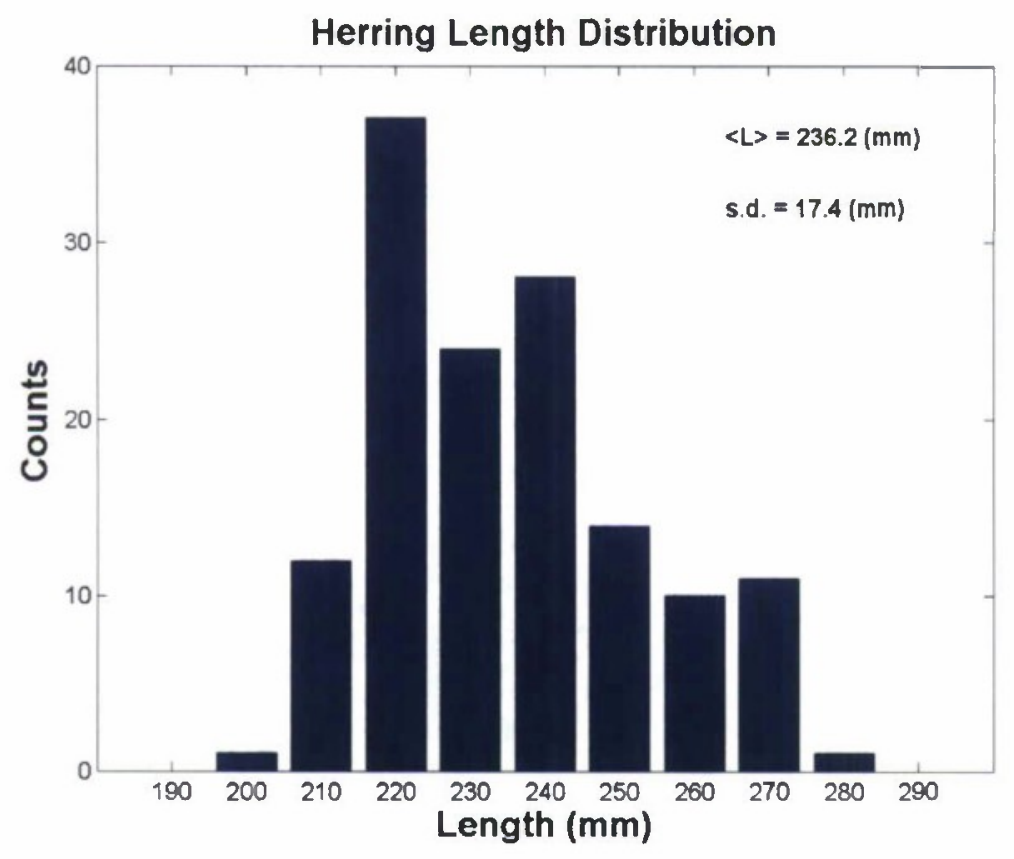

Figure 6b. Size distribution of herring. 


\section{ESTIMATES OF FISH DENSITY}

\section{Using resonance classification at $2-6 \mathrm{kHz}$}

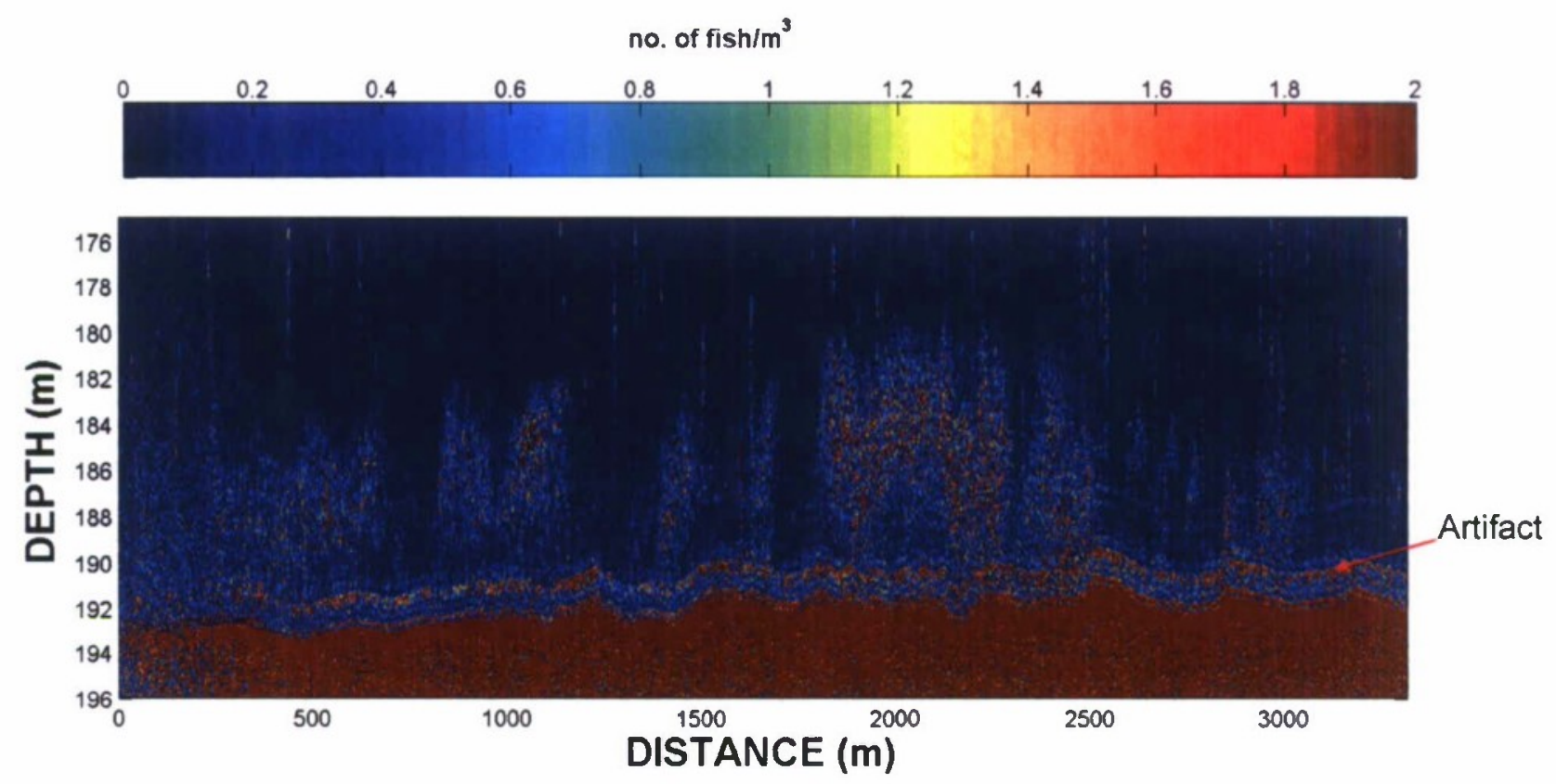

Figure 7. Spatial distribution of numerical density of herring determined unambiguously from broadband resonance data using WHOI mid-frequency system (2005 experiment). 


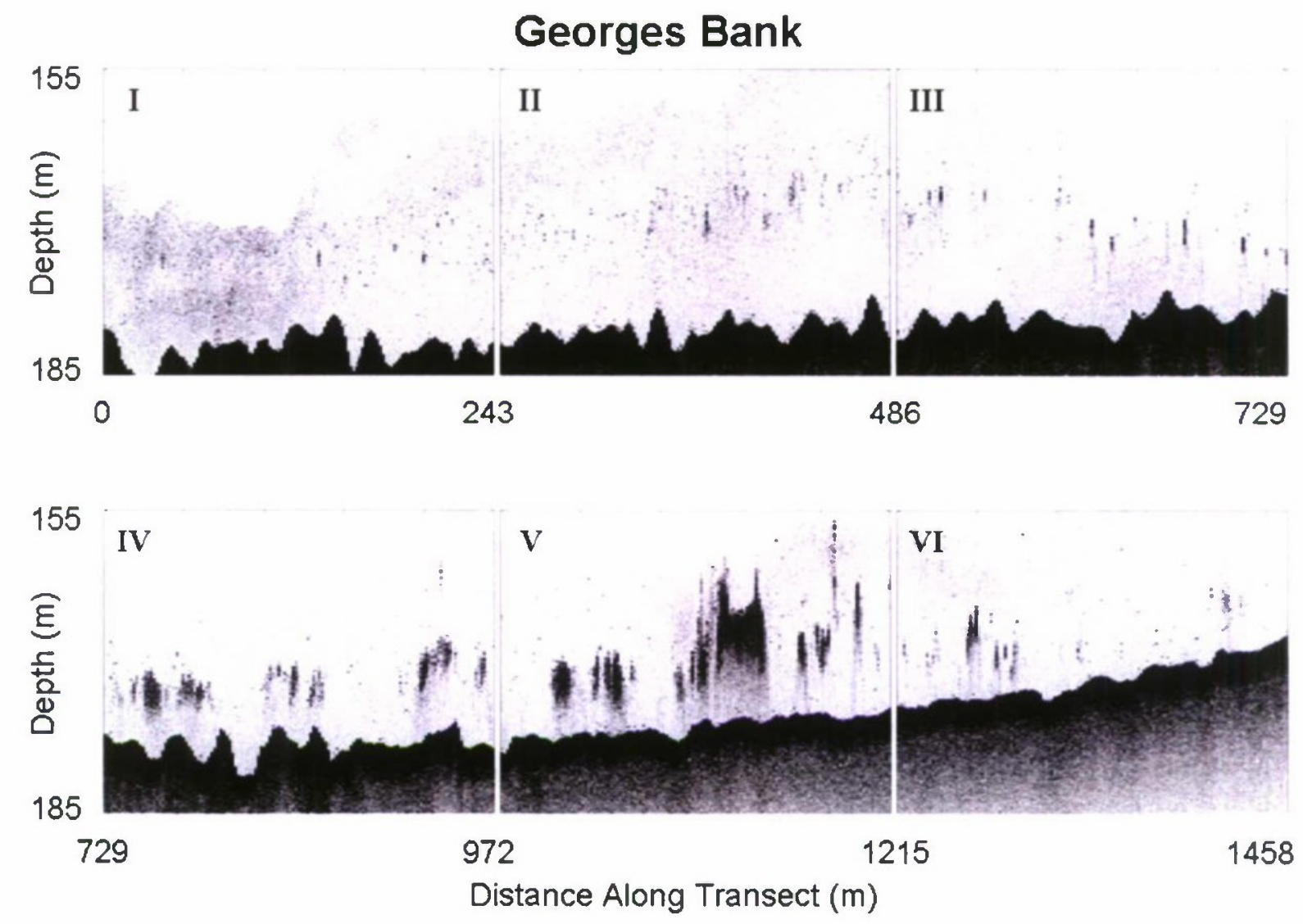

Figure 8. Fish in different stages of social behavior- dispersed (segment I) through grouped (segment V). These unique observations of these bottom-dwelling fish were made with the WHOI short-range downward-looking system towed deep in the water just above the fish in 2007. The black images above the seafloor correspond to the fish. 


\section{Down-looking System}
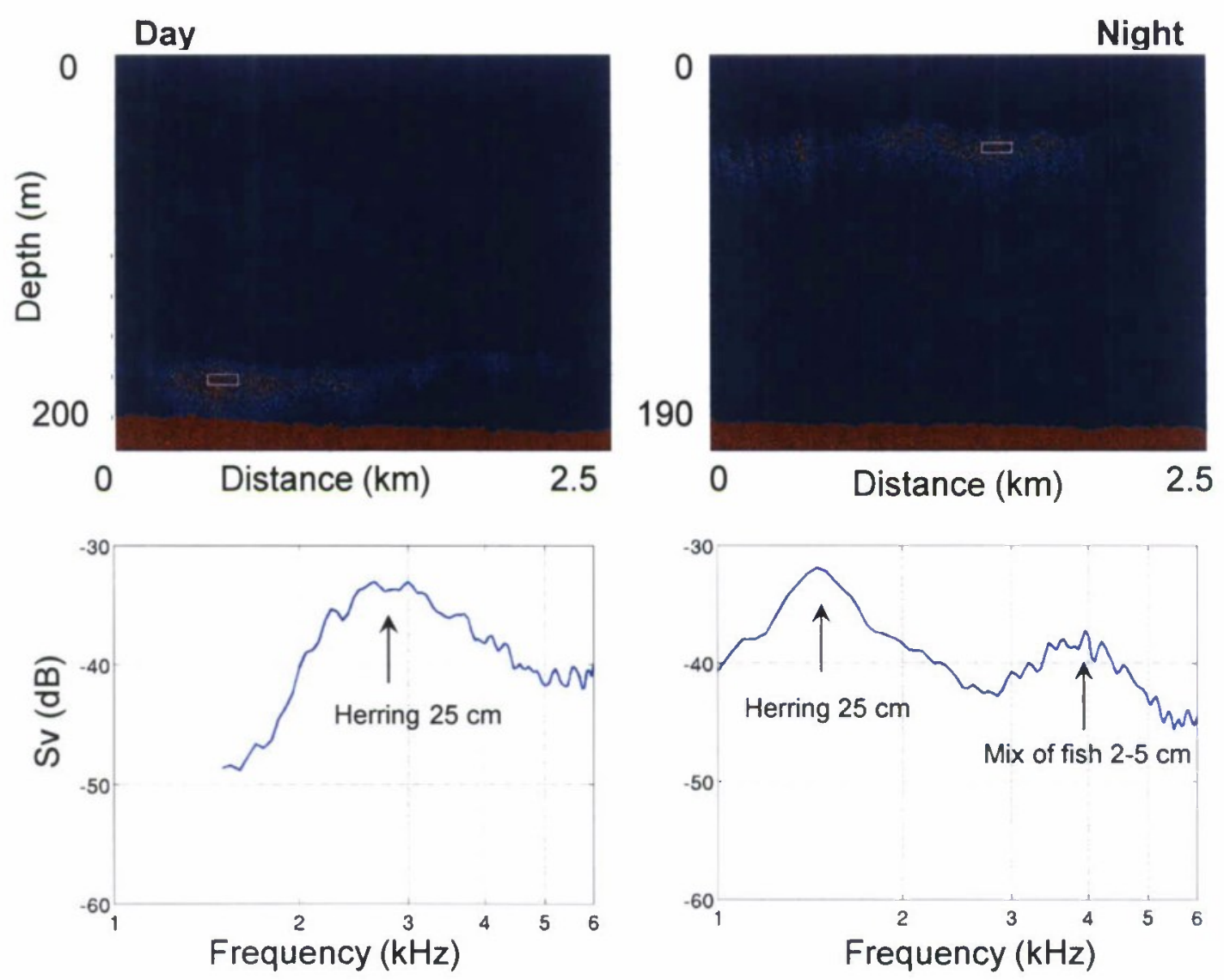

Figure 9. Mid-frequency echograms collected in the day (left) and night (right) by WHOI shortrange downward-looking system in 2008. The resonance from the herring is shown to decrease once they migrate to shallow depths. Also, in the upper water column (right) the broadband data are shown to discriminate (spectrally) between small and large fish. Note that, although the system response is most sensitive at frequencies above $1.5 \mathrm{kHz}$, the scattering was so strong in the data in the right plots that the echoes were detected below $1.5 \mathrm{kHz}$ as shown. 


\section{Resonance classification of mixed assemblages}

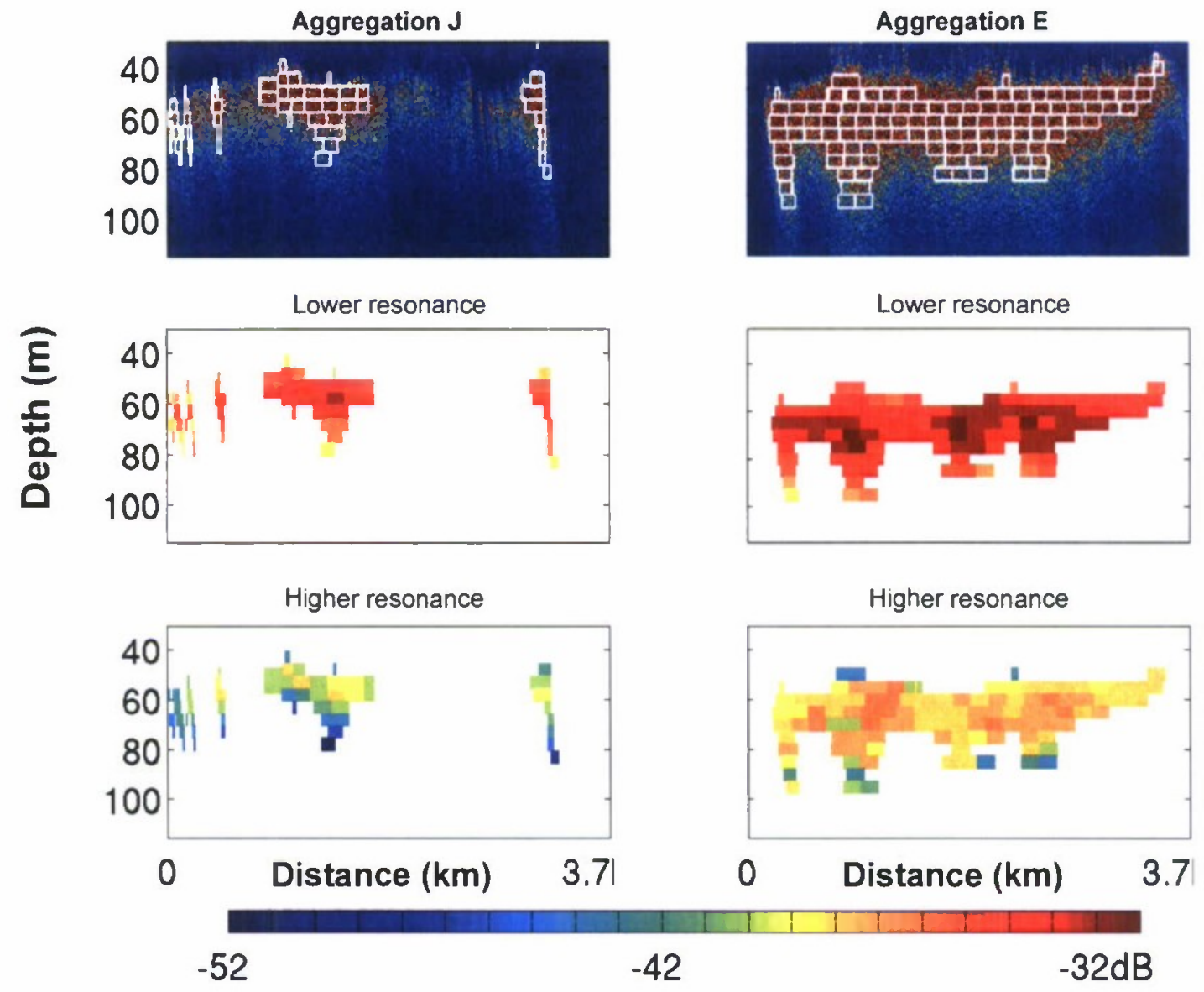

Figure 10. Mixed assemblages of fish were studied in 2008 with the WHOl short-range downward-looking mid-frequency system. Bimodal resonance data, such as shown in Fig. 9, are used to estimate as a function of depth the relative numerical density of each size class of fish (large and small) throughout each patch. In Aggregation J, the larger fish are shown to be nearly uniformly distributed throughout the patches, while the density of smaller fish decrease dramatically with depth (density at bottom of patch is less than $1 / 10$ density at top of patch). Here, volume scattering strength is plotted in the lower four panels for each resonance. Numerical density of each size class is assumed to vary directly with volume scattering strength in this interpretation. 


\section{Long-range horizontal-looking sonar}

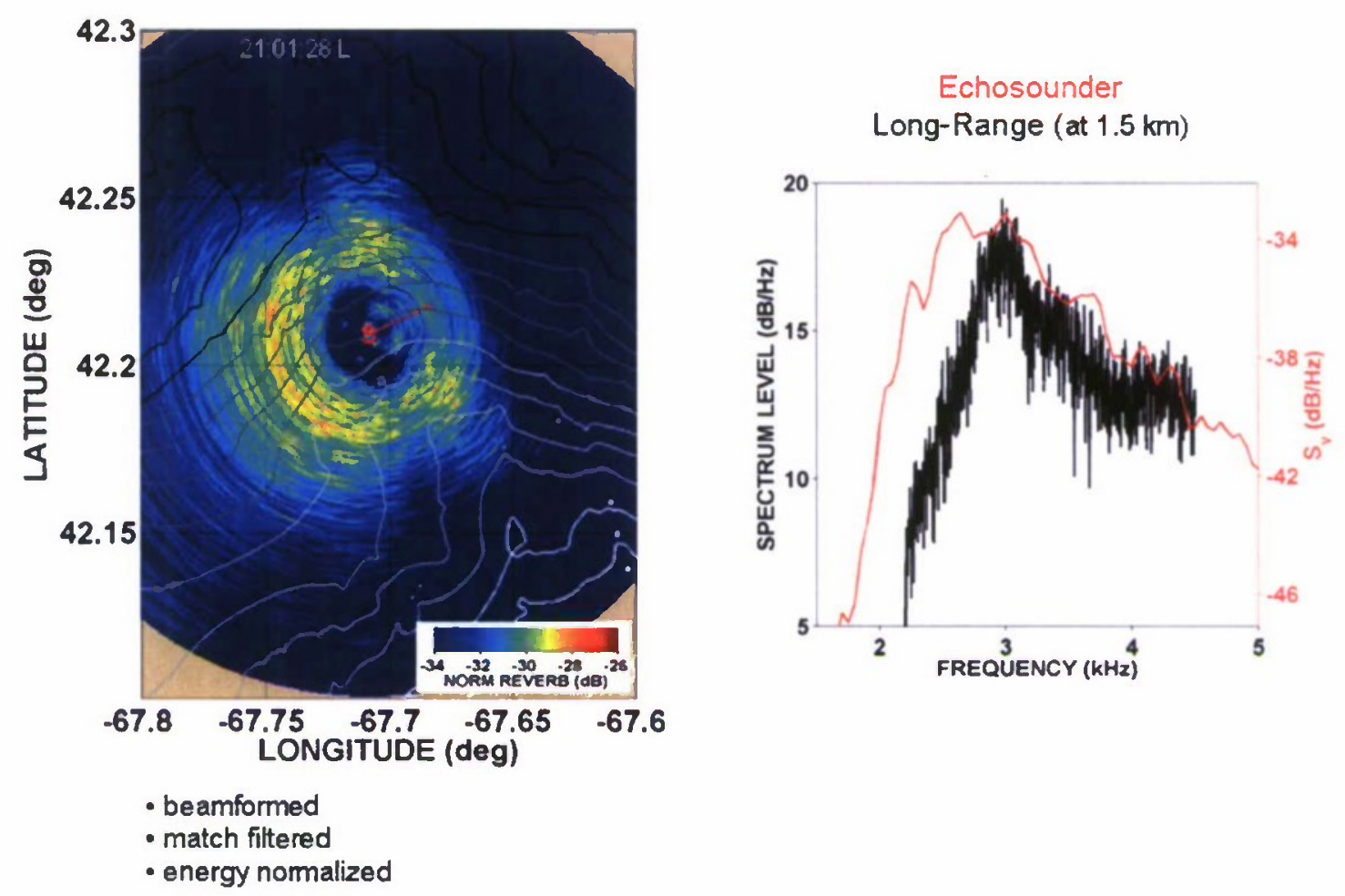

Figure 11. Data collected by NRL with long-range horizontal-looking mid-frequency system in 2008. Patches of fish were observed out to $10 \mathrm{~km}$ and with a resonance of about $3 \mathrm{kHz}$. System was using towed horizontal line array. 


\section{Temporal variability of patches}

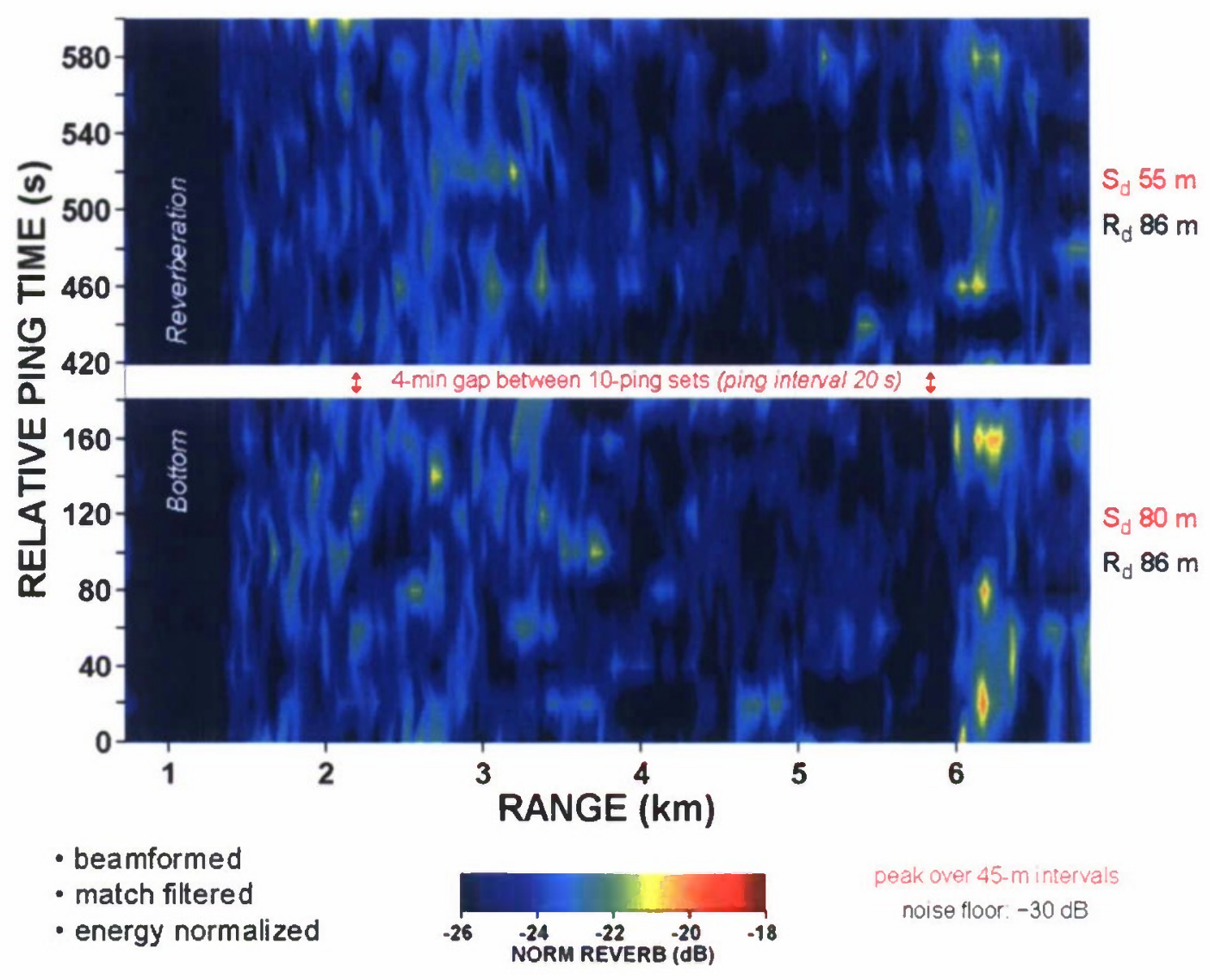

Figure 12. Time series of 20 pings from NRL long-range system while at fixed station (vertical line array configuration). A 1-sec.-long chirp signal spanning $2.5-3.5 \mathrm{kHz}$ was used in this particular measurement. The energy normalized matched filter data show the temporal variability of patches of fish at $6 \mathrm{~km}$ range. 